\title{
Hijacking the Progress of Addiction: Looking at $\beta$-Arrestin 1 and $\beta$-Arrestin 2 to Cognize Drugs of Abuse
}

Md. Sahab Uddin ${ }^{* *}$ and Sadeeq Muhammad Sheshe ${ }^{2}$

${ }^{1}$ Department of Pharmacy, Southeast University, Dhaka, Bangladesh

${ }^{2}$ Department of Biosciences, COMSATS Institute of Information Technology, Islamabad, Pakistan

\section{Editorial}

The reward system comprises of a group of neural structures accountable to mediate distinct behavioural change, learning and optimistic emotions particularly ones that comprise feeling (i.e., love, euphoria and ecstasy) as a central cog $[1,2]$. The nucleus accumbens (NAc) is the most central region of the reward system. It is an important structure of the basal ganglia receiving information from cortical and limbic structures and facilitates persistent behaviours [3-5]. Enduring exposure of different classes of drugs disturbs plasticity of this region, promoting an extreme desire for drug seeking (Figure 1). $\beta$-arrestin 1 and $\beta$-arrestin 2 are abundantly expressed scaffolding proteins carrying out diverse functions in the cell. These adapter proteins are able to form complexes with many G-protein coupled receptors (GPCRs) after binding of a ligand resulting in activation of the receptors [6]. In fact, $\beta$-arrestins have been reported to play major and critical roles in related processes of GPCR desensitization and sequestration consequently leading to inactivation of G-protein and signal cascades [7]. This is said to cause inhibition of cellular responses to stimuli such as hormones, neurotransmitters, or sensory signals. In the central nervous system, $\beta$-arrestins are copiously expressed.

In a study, Mittal et al. examined the key mechanisms involved in behavioural performances mediated by $\beta$-arrestin 1 [8]. Using a mice model lacking $\beta$-arrestin 1 , they studied the role of this scaffolding protein in reward-driven behaviours and striatal glutamatergic role. They observed that mice lacking the $\beta$-arrestin 1 were slow responses to self-administration of cocaine and quenching of the response. The researchers revealed the difficulty in learning advocated by natural food reward, proposing distortion in the reward system [8]. It has been observed that glutamate plays a major role in processes (i.e., reinforcement, sensitization, context conditioning, habit and reinforcement learning, craving and relapse) facilitating development and managing of addiction [9]. They later to undergo cocaine selfadministration tested the strength of the glutamatergic synaptic response in wild-type (WT) and knock-out (KO) medium spinal neurons of the NAc shell in naive animals. There were an increase in the $\alpha$-amino3-hydroxy-5-methylisoxazole-4-propionate (AMPA)/N-methylD-aspartate (NMDA) ratio and a relative lack of GluN2B-enriched $\mathrm{N}$-methyl $\mathrm{D}$-aspartate receptor subtype $2 \mathrm{~B}$ (NMDARs) in naïve $\mathrm{KO}$ versus WT medium spiny neurons. Lim domain kinase (LIMK) is a kinase that phosphorylates thus inactivating cofilin. Using LIMK the researchers showed that both $\beta$-arrestin 1, as well as LIMK, regulates the AMPA/NMDA ratio and GluN2B-NMDARs. The researcher observed that self-administration of cocaine augmented the AMPA/NMDA ratio and GluN2B-NMDARs in spinal medium neurons of WT mice. But for $\mathrm{KO}$ spinal medium neurons, an increase in AMPA/NMDA ratio was detected accompanied by fewer GluN2B-NMDARs and a presence of calcium-penetrable AMPARs [8]. The study suggested that ifenprodil is an inhibitor of NMDA receptor specifically of glycine-binding NMDA receptor (GluN1) and glutamate-binding NMDA receptor subunit 2 (GluN2B) [10]. Furthermore, ifenprodil blocks GIRK channels and interacts with al adrenergic, serotonin and sigma receptors [11].

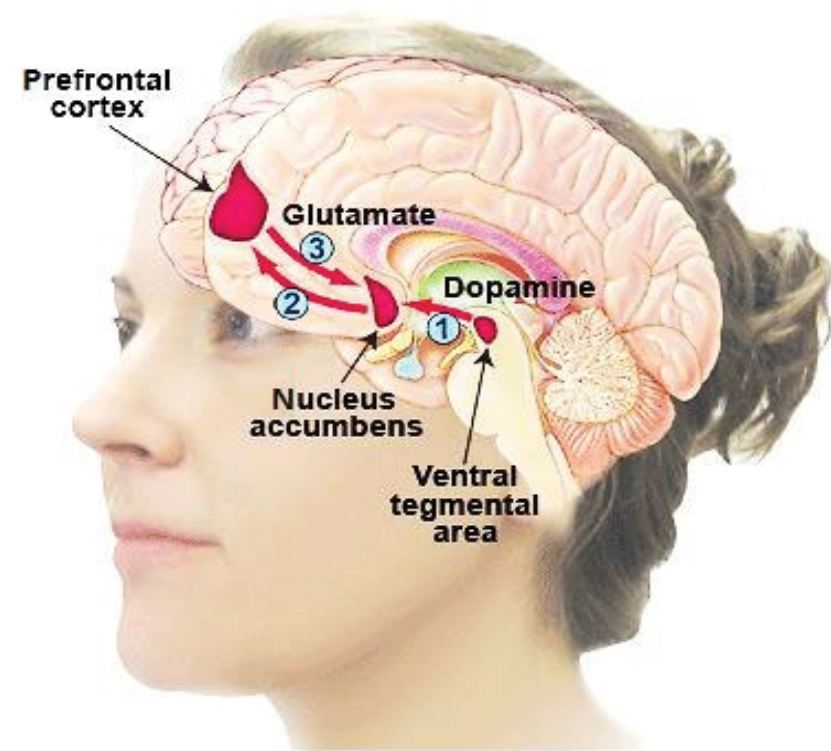

Figure 1: The release of dopamine into the nucleus accumbens is the way of the brain gets pleasure signals. Feeling pleasure abets us to repeat behaviours that are vital for survival. But, drugs of abuse also causes alike phenomenon and in some cases, these drugs are accountable for augmented dopamine release than the natural rewards.

Lastly, the researchers administered ifenprodil as a GluN2B antagonist, to the NAc shell of WT mice in other to study effects of reduced basal GluN2B-NMDARs in reward-processing observed in KO mice which resulted into a significantly reduced food-motivated behaviour. They finally concluded that lack of $\beta$-arrestin 1 result in specific deficits in cocaine and food-related behaviours and in glutamatergic synaptic asset and subunit construction [8].

Conversely $\beta$-arrestin 2 interacts directly with receptors as well as signalling pathways that facilitate behavioural changes due to effects of drugs of abuse. Bohn et al. measured conditioned place preference (CPP) to study the effect of $\beta$-arrestin $2 \mathrm{KO}$ in morphine-induced locomotion and reward behaviours [12]. The researchers observed that

*Corresponding author: Md. Sahab Uddin, Department of Pharmacy, Southeast University, Dhaka, Bangladesh, Tel: +8801710220110; E-mail: msu neuropharma@hotmail.com, msu-neuropharma@hotmail.com.

Received: December 06, 2017; Accepted: December 07, 2017; Published: December 10, 2017

Citation: Uddin MS, Sheshe SM (2018) Hijacking the Progress of Addiction: Looking at $\beta$-Arrestin 1 and $\beta$-Arrestin 2 to Cognize Drugs of Abuse. J Psychiatry 21: e114. doi:10.4172/2378-5756.1000e114

Copyright: ( 2018 Uddin MS, et al. This is an open-access article distributed unde the terms of the Creative Commons Attribution License, which permits unrestricted use, distribution, and reproduction in any medium, provided the original author and source are credited 
mice lacking $\beta$-arrestin 2 show efficient morphine reward but blunted morphine-induced locomotion. Similarly, mice lacking $\beta$-arrestin 2 show augmented morphine-induced dopamine release in the striatum with respect to controls [12]. In a study Urs et al. tested morphine CPP and locomotion in order to study the role of $\beta$-arrestin 2 in D1comprising neurons in conditional KO mice that absence $\beta$-arrestin 2 only in D1-comprising cells [13]. Although $\beta$-arrestin 2 interactions with dopamine receptors may change effects of opioid, staffing of $\mu$-opioid receptor by $\beta$-arrestin 2 could also be imperative due to morphine's great magnetism for $\mu$-opioid receptors. The role of $\mu$-opioid agonists to recruit $\beta$-arrestin 2 could have vital behavioural concerns. $\mu$-opioid agonists, for example, morphine, heroin and oxycodone had low levels of endocytosis and recruitment of $\beta$-arrestin 2 although they all have high abuse potential and can cause tolerance and dependence [14-16].

Like morphine, cannabinoid receptor agonists are also abused although can provide pain relief. Both $\mathrm{CB} 1$ and $\mathrm{CB} 2$ cannabinoid receptors recruit $\beta$-arrestin 2. Raehal and Bohn reported that $\beta$-arrestin 2 also affects behavioural changes in many but not all cannabinoid receptor agonists [17].

Bjork et al. examined that mice without $\beta$-arrestin 2 intakes markedly less alcohol at low doses and had abated penchant for alcohol in a two-bottle choice procedure compared to controls [18]. In another study, $\mathrm{Li}$ et al. showed mice with $\beta$-arrestin $2-\mathrm{KO}$ consumed more alcohol, especially at higher doses [19].

$\beta$-arrestins can have copious roles in behavioural responses to addictive drugs. $\beta$-arrestin 1 and $\beta$-arrestin 2 are likely aspirants for controlling the roles of drugs of abuse. However, further studies are obligatory to clarify the neurobiological mechanisms to explicate exactly the tactic by which $\beta$-arrestin 1 and $\beta$-arrestin 2 controls behavioural responses to drugs of abuse, as well as its auspicious potential as a therapeutic target to hijack the progress of addiction.

\section{Acknowledgements}

The authors wish to thank the anonymous reviewer(s)/editor(s) of this article for their constructive reviews.

\section{Competing Interests}

The authors proclaim no competing interests.

\section{References}

1. Schultz W (2015) Neuronal reward and decision signals: From theories to data. Physiol Rev 95: 853-951.

2. Uddin MS (2017) Neurochemistry of love: Can romantic love truly be addictive? J Psychiatry 21: 1-3.
3. Uddin MS, Sufian MA, Kabir MT, Hossain MF, Nasrullah M, et al. (2017) Amphetamines: Potent recreational drug of abuse. J Addict Res Ther 8: 1-12.

4. Uddin MS, Sufian MA, Hossain MF, Kabir MT, Islam MT, et al. (2017) Neuropsychological effects of caffeine: Is caffeine addictive? J Psychol Psychother 7: 1-12.

5. Uddin MS (2017) Sugar and reward system: Is high sugar intake generating akin effects like drugs of abuse? Ment Health Addict Res 2: 1-2.

6. Smith JS, Rajagopal S (2016) The $\beta$-arrestins: Multifunctional regulators of $G$ protein-coupled receptors. J Biological Chemis 291: 8969-8977.

7. Luttrell LM, Lefkowitz RJ (2002) The role of beta-arrestins in the termination and transduction of G-protein-coupled receptor signals. J Cell Sci 115: 455465.

8. Mittal N, Minasyan A, Romaneschi N, Hakimian JK, Gonzalez-Fernandez G et al. (2017) Beta-arrestin 1 regulation of reward-motivated behaviors and glutamatergic function. PLoS One 12: e0185796.

9. Tzschentke TM, Schmidt WJ (2003) Glutamatergic mechanisms in addiction Mol Psychiatry 8: 373-382.

10. Korinek M, Kapras V, Vyklicky V, Adamusova E, Borovska J, et al. (2011) Neurosteroid modulation of $\mathrm{N}$-methyl-d-aspartate receptors: Molecular mechanism and behavioural effects. Steroids 76: 1409-1418.

11. Kobayashi T, Washiyama K, Ikeda K (2005) Inhibition of $G$ protein-activated inwardly rectifying $\mathrm{K}^{+}$channels by ifenprodil. Neuropsychopharmacology 31 : 516-524.

12. Bohn LM, Gainetdinov RR, Sotnikova TD, Medvedev IO, Lefkowitz RJ, et al. (2003) Enhanced rewarding properties of morphine, but not cocaine, in Barrestin-2 knock-out mice. J Neurosci 23: 10265.

13. Urs NM, Gee SM, Pack TF, McCorvy JD, Evron T, et al. (2016) Distinct cortical and striatal actions of a $\beta$-arrestin-biased dopamine D2 receptor ligand reveal unique antipsychotic-like properties. Proc Natl Acad Sci USA 113: E8178-E8186

14. Keith DE, Anton B, Murray SR, Zaki PA, Chu PC, et al. (1998) mu-Opioid receptor internalization: opiate drugs have differential effects on a conserved endocytic mechanism in vitro and in the mammalian brain. Mol Pharmacol 53 377-384.

15. Whistler JL, von Zastrow M (1998) Morphine-activated opioid receptors elude desensitization by beta-arrestin. Proc Natl Acad Sci USA 95: 9914-9919.

16. Zhang J, Ferguson SS, Barak LS, Bodduluri SR, Laporte SA, et al. (1998) Role for $G$ protein-coupled receptor kinase in agonist-specific regulation of muopioid receptor responsiveness. Proc Natl Acad Sci USA 95: 7157-7162.

17. Raehal KM, Bohn LM (2014) $\beta$-Arrestins: Regulatory role and therapeutic potential in opioid and cannabinoid receptor-mediated analgesia. Handb Exp Pharmacol 219: 427-443.

18. Björk K, Rimondini R, Hansson AC, Terasmaa A, Hyytiä P, et al. (2008) Modulation of voluntary ethanol consumption by beta-arrestin 2 . FASEB $\mathrm{J} 22$ 2552-2560.

19. Li H, Tao Y, Ma L, Liu X, Ma L (2013) $\beta$-Arrestin-2 inhibits preference for alcohol in mice and suppresses Akt signalling in the dorsal striatum. Neurosci Bull 29 531-540. 